\title{
Growth plate senescence is associated with loss of DNA methylation
}

\author{
Ola Nilsson, Robert D Mitchum Jr, Lenneke Schrier, \\ Sandra P Ferns, Kevin M Barnes, James F Troendle ${ }^{1}$ \\ and Jeffrey Baron
} Developmental Endocrinology Branch and ${ }^{1}$ Biometry and Mathematical Statistics Branch, National Institute of Child Health and Human Development,
National Institutes of Health, Bethesda, Maryland 20892, USA
(Requests for offprints should be addressed to O Nilsson, National Institutes of Health, NICHD, Building CRC Room 1-3330, 10 Center Dr. MSC 1103,
Bethesda, Maryland 20892-1103, USA; Email: ola.nilsson@nih.gov)

\begin{abstract}
The overall body size of vertebrates is primarily determined by longitudinal bone growth at the growth plate. With age, the growth plate undergoes programmed senescence, causing longitudinal bone growth to slow and eventually cease. Indirect evidence suggests that growth plate senescence occurs because stem-like cells in the growth plate resting zone have a finite proliferative capacity that is gradually exhausted. Similar limits on replication have been observed when many types of animal cells are placed in cell culture, an effect known as the Hayflick phenomenon. However, we found that the number of population doublings of rabbit resting zone chondrocytes in culture did not depend on the age of the animal from which the cells were harvested, suggesting that the mechanisms limiting replicative capacity of growth plate chondrocytes in vivo are distinct from those in vitro. We also observed that the level of DNA methyla-
\end{abstract}

tion in resting zone chondrocytes decreased with age in vivo. This loss of methylation appeared to occur specifically with the slow proliferation of resting zone chondrocytes in vivo and was not observed with the rapid proliferation of proliferative zone chondrocytes in vivo (i.e. the level of DNA methylation did not change from the resting zone to the hypertrophic zone), with proliferation of chondrocytes in vitro, or with growth of the liver in vivo. Thus, the overall level of DNA methylation decreases during growth plate senescence. This finding is consistent with the hypothesis that the mechanism limiting replication of growth plate chondrocytes in vivo involves loss of DNA methylation and, thus, loss of DNA methylation might be a fundamental biological mechanism that limits longitudinal bone growth in mammals, thereby determining the overall adult size of the organism.

Journal of Endocrinology (2005) 186, 241-249

\section{Introduction}

Overall body dimensions of mammals are primarily determined by growth of the skeleton, particularly longitudinal growth of the long bones and vertebrae. Longitudinal bone growth, in turn, results from chondrocyte proliferation in the growth plates. With age, this proliferation slows down, causing longitudinal bone growth to slow and eventually stop (Walker \& Kember 1972). Also with increasing age, the growth plate undergoes structural changes including a decrease in the height of the growth plate, a decrease in the number of chondrocytes in the individual zones, as well as a decrease in the size of the individual hypertrophic chondrocytes. These functional and structural changes appear not to be due to a systemic mechanism but, instead, based on growth plate transplantation experiments (Stevens et al. 1999), to a mechanism intrinsic to the growth plate (Baron et al. 1994, Gafni et al. 2001). This process, termed growth plate senescence, appears to be a function, not of time per se, but rather of the number of replications that the growth plate chondrocytes have undergone (Baron et al. 1994, Gafni et al. 2001). Indirect evidence suggests that stem-like cells, located in the resting zone of the growth plate (Abad et al. 2002), have a finite proliferative capacity which is gradually exhausted, thus producing the growth deceleration and other senescent changes (Weise et al. 2001).

Similar limits on replication have been observed when many types of animal cells are placed in cell culture, an effect known as the Hayflick phenomenon (Hayflick \& Moorhead 1961). In such cell cultures, the rate of proliferation decreases until it eventually comes to an irreversible stop (Stanulis-Praeger 1987). The stopping point is determined, not by time in culture, but by the number of cell divisions undergone (Hayflick 1965, Goldstein \& Singal 1974, Kaji \& Matsuo 1979). Thus, the limits on replication of cultured cells is similar to the proposed limits on replication of growth plate chondrocytes in vivo. Although it has 
been suggested that both phenomena may involve a cellcycle counter, a cellular mechanism that is progressively changed with each cell division, it is not known whether the underlying mechanisms responsible for these two phenomena are the same.

One mechanism that has been proposed to explain replicative senescence involves epigenetic changes in methylation of genomic DNA (Wilson \& Jones 1983, Holliday 1985, Young \& Smith 2001). Some CG sequences in mammalian genomic DNA are methylated on the cytosine moiety. When DNA is replicated, the new strand is initially not methylated. However, DNA methyltransferase 1, a maintenance methylase, recognizes the hemimethylated CGs and adds the missing methyl groups (Wigler et al. 1981, Stein et al. 1982). If maintenance methylation is incomplete, methylation levels may gradually decrease with repeated cell replication. Thus, the level of DNA methylation could serve as a cell-cycle counter. The level of DNA methylation can then affect gene expression, in part by altering interaction of transacting elements with the promoter region and in part by altering histone modification, and thus chromatin structure (Eden et al. 1998, Jones \& Laird 1999). There is evidence that such epigenetic changes may contribute to replicative senescence and terminal differentiation in some cell types (Wilson \& Jones 1983, Fairweather et al. 1987, Young \& Smith 2001). In particular, growth plate chondrocytes cultured at high density and exposed to a demethylating agent (5-azacytidine), undergo hypertrophic differentiation (Cheung et al. 2001. Furthermore, disruption of PASG (proliferation-associated SNF2like gene), PASG, which is required for normal maintainance of DNA methylation, results in growth retardation and premature aging (Sun et al. 2004). These observations raise the possibility that the limits on replication of growth plate chondrocytes may involve changes in DNA methylation and other related epigenetic modifications.

We first hypothesized that the limits on replication of growth plate chondrocytes in vivo involve the same cellular mechanisms as replicative senescence in vitro (the Hayflick phenomenon). This hypothesis predicts that growth plate chondrocytes taken from older animals and placed in cell culture will undergo fewer cell divisions before undergoing replicative senescence than will chondrocytes from younger animals. We next hypothesized that the underlying mechanism involves loss of DNA methylation, which acts as a cell-cycle counter that limits proliferation of growth plate chondrocytes in vivo and in vitro. This hypothesis predicts that the level of DNA methylation decreases with replication of growth plate chondrocytes in vitro and in vivo.

\section{Materials and Methods}

\section{Animals}

New Zealand White rabbits (Covance Research Products, Denver, PA, USA) were maintained and used in accordance with the Guide for the Care and Use of Laboratory Animals (National Research Council 2003). All animals received National Institutes of Health open formula rabbit ration (NIH 32) and water ad libitum. The Animal Care and Use Committee (National Institute of Child Health and Human Development, National Institutes of Health) approved all experiments reported here. Animals were used on gestational day 29 (fetal), and at postnatal week 4 and 16, except for the assessment of in vivo proliferation, when fetal, 5-, and 16-week-old animals were used. The groups were chosen in order to obtain one time-point at rapid (fetal), one at intermediate (4-5 weeks), and one at slow growth (16 weeks) (Masoud et al. 1986).

\section{Assessment of in vivo proliferation}

To assess in vivo proliferation in the proliferative zone, a pregnant doe (gestational day 29), and 5- and 16-week-old male rabbits were injected with 5-bromo-2'-deoxyuridine (BrdU, 50 mg/kg; Sigma-Aldrich Corp., St Louis, MO, USA) 90 min before they were killed. BrdU-labeled cells were detected in the proximal tibial growth plate by immunohistochemistry using BrdU in situ detection kit II (BD Biosciences Pharmingen, San Diego, CA, USA) according to the manufacturer's instructions, except that antigen-retrieval time was extended to $15 \mathrm{~min}$. The number of BrdU-labeled chondrocytes was counted in 25 columns per animal ( $n=3$ per age group) and averaged.

\section{Dissection of growth plates}

Rib cartilage from fetal, 4-, and 16-week-old rabbits and distal ulnar growth plates from fetal and 4-week-oldrabbits were stripped of soft tissue and perichondrium, and separated from bone tissue. For dissection of the resting zone from rib cartilage, the proliferative and hypertrophic zones were separated from the rib cartilage by an incision immediately medial to the perichondrial indentation that is visible when the perichondrium has been removed, also called the ossification groove of Ranvier (Shapiro et al. 1977). The next $1 \mathrm{~mm}$ of rib cartilage was regarded as the resting zone and processed for cell culture and assessment of global DNA methylation. For the distal ulnae, the perichondrium was first removed. The metaphyseal margin of the growth plate was separated from the metaphysis by manual pressure. The cartilaginous growth plate was excised by an incision along its epiphyseal margin. The resting zone was then isolated by an incision immediately distal to the perichondrial indentation. The proliferative and hypertrophic zones were separated by incisions made between the distal two-thirds and the proximal one-third of the remaining pieces. The individual zones were processed for assessment of global DNA methylation.

\section{Chondrocyte cell culture}

For the study of replicative capacity in vitro, resting zone cartilage from the rib growth plates of fetal $(n=5)$, 
4- $(n=4)$, and 16-week-old $(n=4)$ male rabbits were used. Single cell suspension of chondrocytes was obtained by collagenase digestion of cartilage (Wroblewski \& EdwallArvidsson 1995). Pieces of cartilage were incubated with $0.1 \mathrm{mM}$ EDTA in phosphate-buffered saline (PBS; $\mathrm{pH} 7 \cdot 4$ ) for $15 \mathrm{~min}$ at $37^{\circ} \mathrm{C}$ followed by incubation in $0.125 \%$ trypsin (Invitrogen Corporation, Carlsbad, CA, USA) for $30 \mathrm{~min}$ at $37^{\circ} \mathrm{C}$. The pieces were then minced into smaller pieces $(<0.5 \mathrm{~mm})$ using a scalpel blade and incubated with $0 \cdot 2 \%$ collagenase type $1 \mathrm{~A}$ (Sigma-Aldrich Corp.) in PBS (pH 7.4) in an incubator shaker at $37^{\circ} \mathrm{C}$. The collagenase solution was replaced every $45 \mathrm{~min}$ until the cartilage pieces had been digested into a suspension (1-3 h). The cell suspension was filtered through a $100 \mu \mathrm{m}$ cell strainer (BD Falcon/BD Biosciences, Bedford, MA, USA), and washed three times in Dulbecco's modified Eagles' medium (Biosource, Camarillo, CA, USA) supplemented with $10 \%$ fetal bovine serum (Biosource), gentamicin $(50 \mu \mathrm{g} / \mathrm{ml}$; Biosource), fungizone $(2 \mu \mathrm{g} / \mathrm{ml}$; Biosource), ascorbic acid $(50 \mu \mathrm{g} / \mathrm{ml}$; Sigma-Aldrich Corp.), and glutamine (2 mM; Biosource). Cells were seeded in duplicate $35 \mathrm{~mm}$ wells (Corning Incorporated, Corning, NY, USA) at $1250 \mathrm{cells} / \mathrm{cm}^{2}$ in the same medium. Medium was changed three times per week and the cells were subcultured at approximately $90 \%$ confluence. The number of cells was counted in ten random fields $\left(0 \cdot 4 \mathrm{~cm}^{2}\right)$ three times per week using an inverted microscope. At each split, cells were collected for assessment of global DNA methylation. In order to present the proliferation data as continuous growth curves, at each split, the last cell count before the split was divided by the first cell count after the split. All cell counts following that particular split were then multiplied by that quotient.

\section{Histochemistry on cultured chondrocytes}

For staining of phenotypic- and senescence-related markers, chondrocytes cultured on glass chamber slides (Nalge Nunc International, Naperville, IL, USA) were washed in PBS, fixed in $2 \%$ phosphate-buffered formalin $(\mathrm{pH} 7 \cdot 4)$ for $10 \mathrm{~min}$, and washed three times in distilled water.

Glycosaminoglycans For alcian blue staining of glycosaminoglycans, fixed cells were washed once in $3 \%$ acetic acid and then incubated with a solution containing $0.5 \%$ alcian blue (Bio-Rad, Hercules, CA, USA) in 3\% acetic acid ( $\mathrm{pH} 2 \cdot 5)$ for $30 \mathrm{~min}$ at room temperature.

Alkaline phosphatase Alkaline phosphatase activity
was detected by enzyme histochemistry using the
simultaneous-coupling azo dye method. Chondrocytes
grown on chamber slides were incubated for $30 \mathrm{~min}$
at room temperature in a solution containing $2 \%$
$\mathrm{~N}, \mathrm{~N}-$ dimethylformamide (Sigma-Aldrich Corp.), $0 \cdot 2 \mathrm{M}$
Tris-HCl buffer (pH $8 \cdot 3$ ), $0 \cdot 005 \%$ naphthol AS-BI phosphate (2-naphthalenecarboxamide, 7-bromo-N-(2methoxyphenyl)-3-(phosphonooxy), disodium salt; (SigmaAldrich Corp.) and $0 \cdot 1 \%$ fast red Texas red salt (SigmaAldrich Corp.).

Senescence-related $\boldsymbol{\beta}$-galactosidase Senescencerelated $\beta$-galactosidase staining was performed using a procedure previously described (Dimri et al. 1995). Fresh senescence-related $\beta$-galactosidase stain solution was prepared by mixing $1 \mathrm{ml} 2 \%$ 5-bromo-4-chloro-3indolyl $\beta$-D-galactoside (Sigma-Aldrich Corp.) in N,Ndimethylformamide with $19 \mathrm{ml} 40 \mathrm{mM}$ citrate-phosphate buffer ( $\mathrm{pH} 6.0)$ containing $5 \mathrm{mM}$ potassium ferrocyanide, $5 \mathrm{mM}$ potassium ferricyanide, $150 \mathrm{mM} \mathrm{NaCl}$, and $2 \mathrm{mM}$ $\mathrm{MgCl}_{2}$. Fixed chondrocytes were incubated with fresh stain solution for $16 \mathrm{~h}$ at $37^{\circ} \mathrm{C}$.

\section{Assessment of global DNA methylation}

The methylation status at MspI restriction endonuclease recognition sites (CCGG) was determined using a procedure described by Bestor et al. (1984) with some modifications. DNA was extracted from pieces of the individual zones of distal ulnar growth plates of fetal $(n=8)$ and 4-week-old-rabbits $(n=9)$ and from rib resting zone cartilage and liver of fetal, 4-, and 16-week-old rabbits ( $n=9$ per group) using the Nucleospin tissue kit (Macherey-Nagel GmbH \& Co. KG, Düren, Germany) according to the manufacturer's instruction. The DNA was cleared from contaminating single- and doublestranded RNA by incubation with RNase A $(20 \mu \mathrm{g} / \mathrm{ml}$, $30 \mathrm{~min}, 37^{\circ} \mathrm{C}$; Roche Diagnostics Corp, Indianapolis, IN, USA) at low salt conditions (5 mM Tris-HCl, $\mathrm{pH} 8 \cdot 5$ ), followed by a wash on a Microcon centrifugal filter device (Microcon YM-100 centrifugal filter; Millipore, Bedford, MA, USA). These latter steps were added to the procedure to eliminate small RNA molecules which otherwise yielded extraneous radioactive spots on the thin layer chromatography plate. The resulting samples of DNA $(0.5 \mu \mathrm{g})$ were digested with either MspI (60 U; Promega, Madison, WI, USA) or, as a control, with its methylsensitive isoschizomer HpaII (10 U; New England Biolabs, Beverly, MA, USA) for $2 \mathrm{~h}$ at $37^{\circ} \mathrm{C}$. The digested DNA was recovered by phenol extraction and ethanol precipitation and labeled at the $5^{\prime}$ termini by an exchange labeling reaction using $\left[\gamma^{32} \mathrm{P}\right] \mathrm{ATP}$ $(3000 \mathrm{Ci} / \mathrm{mmol} ; 10 \mu \mathrm{Ci} /$ sample; Amersham Biosciences Corp., Piscataway, NJ, USA) and T4 polynucleotide kinase (Invitrogen Corporation) according to the manufacturer's instruction. Unincorporated $\left[\gamma_{-}{ }^{32} \mathrm{P}\right] \mathrm{ATP}$ was removed using a micro Bio-Spin P-30 column (Bio-Rad). The samples were precipitated with ethanol, dissolved in $50 \mathrm{mM}$ sodium acetate ( $\mathrm{pH} 5 \cdot 2)$, and digested into single nucleotides with nuclease P1 $(100 \mu \mathrm{g} / \mathrm{ml}$; Sigma-Aldrich Corp.) at $50{ }^{\circ} \mathrm{C}$ for $2 \mathrm{~h}$. The samples were lyophilized and then dissolved in $7 \mu \mathrm{l}$ distilled water. Three microliters 
of each sample were spotted onto cellulose thin-layer chromatography plates (EM Science, Gibbstown, NJ, USA), and chromatography was performed in isobutyric acid- $\mathrm{NH}_{4} \mathrm{OH}$-water $(66: 20: 1)$ for $48 \mathrm{~h}$. The radioactive spots that correlated to methylated and unmethylated deoxycytidine $5^{\prime}$-monophosphate (dCMP) (Fig. 4A) were quantified using a Phosphorimager (Storm 860 Imager; Amersham Biosciences).

\section{Statistics}

Data are expressed as means \pm S.E.M. $P$ values from Kruskal-Wallis and repeated measures model are presented in the Results section, whereas the $P$ values from pairwise comparisons are shown in the Figures. The percent of DNA methylation was calculated as 100 times the radioactivity in the methyl-deoxycytidine $5^{\prime}$ monophosphate (methyl-dCMP) spot divided by the sum of the radioactivity in the methyl-dCMP spot and the dCMP spot (Fig. 4A).

For studies of replicative senescence in cultured chondrocytes, the effect of donor age on the maximal number of population doublings was evaluated by a Kruskal-Wallis test.

The effect of age on the level of DNA methylation in the resting zone of rib growth plate cartilage and liver was evaluated using a Kruskal-Wallis test followed by Wilcoxon rank-sum tests for pairwise comparisons. The $P$ values were adjusted for multiple comparisons using a step-down Bonferroni method with logical constraints.

The overall effects of age and zone on DNA methylation in the distal ulnar growth plate were evaluated by two-way repeated measures ANOVA, followed by $t$-tests corrected for multiple comparison using stepwise permutation tests in order to evaluate changes in individual zones.

The effect of age and population doublings on the level of DNA methylation in cultured chondrocytes was tested by fitting a repeated measures model. For age, the model was repeated measures ANOVA, and for number of population doublings it was a repeated measures linear model.

\section{Results}

Growth plate chondrocyte proliferation in vivo

To determine whether chondrocyte proliferation changes with age in rabbits, proliferation was assessed in the proliferative zone by $\mathrm{BrdU}$ labeling. The number of BrdU-labeled cells declined approximately 3-fold from fetal to 5 -week-old rabbits $(P<0 \cdot 001)$, and approximately another 2.5-fold from 5- to 16-week-old animals $(P=0 \cdot 002$; Fig. 1$)$.

\section{Replicative senescence of resting zone chondrocytes in vitro}

We first tested the prediction that cultured growth plate chondrocytes from older animals will undergo fewer cell

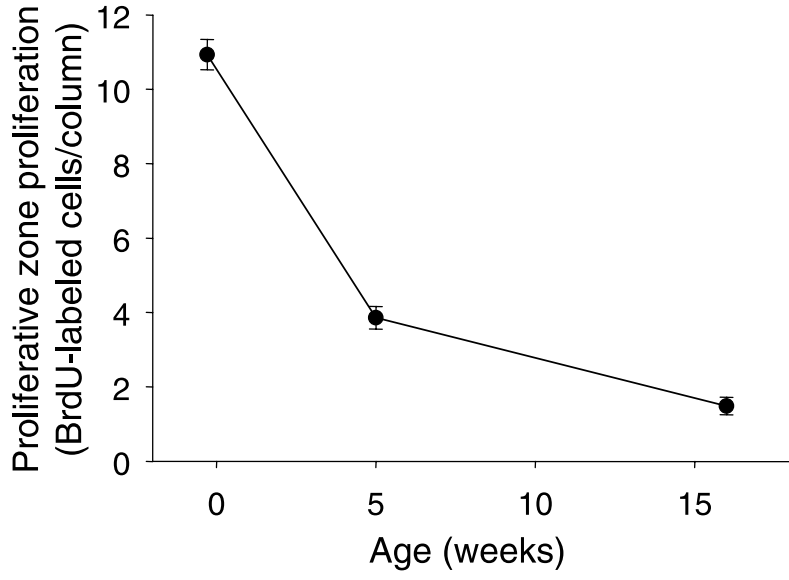

Figure 1 Chondrocyte proliferation in the proliferative zone in vivo. Fetal, $5-$, and 16-week-old rabbits ( $n=3$ per age group) were treated with BrdU 90 min before they were killed and BrdU-labeled cells were detected by immunohistochemistry. The number of BrdU-labeled chondrocytes per column decreased with age. $P<0.001$ by ANOVA.

divisions before undergoing replicative senescence than will chondrocytes from younger animals. Resting zone chondrocytes extracted from fetal, 4-, and 16-week-old male rabbits proliferated for approximately 50 days and underwent three passages (with increasing intervals) before reaching senescence (Fig. 2). During this time, chondrocytes from animals of different ages underwent a similar number of population doublings $(13 \cdot 1 \pm 1 \cdot 1$ vs $14 \cdot 6 \pm 0 \cdot 6$ vs $14 \cdot 3 \pm 0 \cdot 8$; fetal vs 4 weeks vs 16 weeks respectively, $P=0 \cdot 36$ ). Chondrocytes in primary culture were small, had a round or polygonal shape, and stained for alcian blue and alkaline phosphatase activity, but not for senescence related $\beta$-galactosidase (Fig. 3A-C). In contrast, chondrocytes that were becoming senescent were larger, only stained faintly or not at all for alcian blue and alkaline phosphatase activity, but showed an increased senescencerelated $\beta$-galactosidase activity (Fig. 3D-F).

\section{Effect of age on global DNA methylation in growth plate cartilage and liver}

To test the prediction that DNA methylation decreases with replication of growth plate chondrocytes in vivo, we measured the level of DNA methylation in growth plate cartilage from animals of different ages. The level of global DNA methylation decreased with age in the resting zone of rib growth plates from fetal, 4-, and 16-week-old rabbits $(P=0.004$; Fig. 4B). DNA methylation also decreased with age in all three zones of the distal ulnar growth plates of fetal and 4-week-old rabbits $(P<0 \cdot 001$; Fig. 4C). Within each age, there was no significant difference between the individual zones of the ulnar growth plate. To determine whether the decline in DNA methylation occurred in a tissue that retains its ability to proliferate, we 


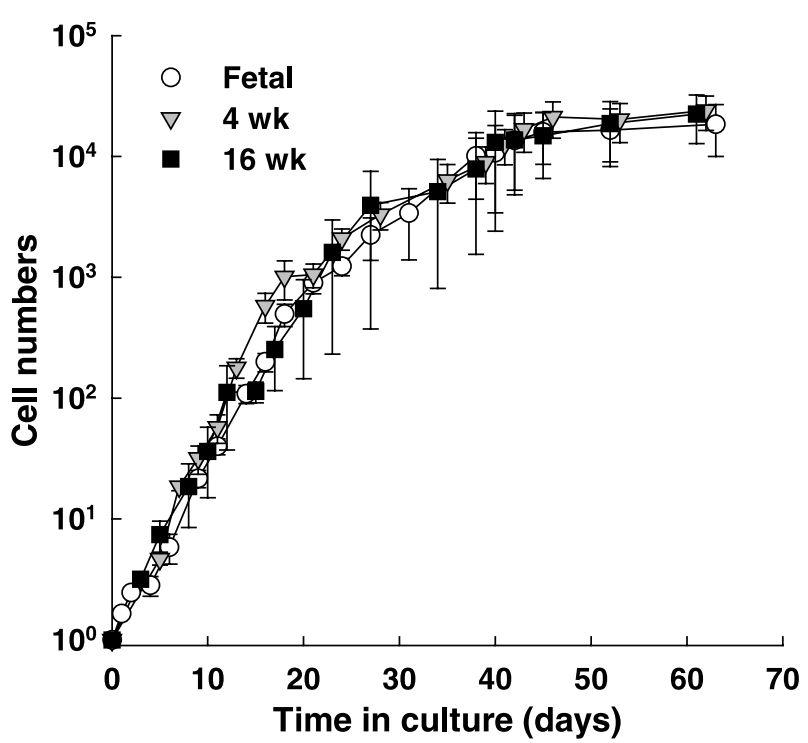

Figure 2 Cumulative cell numbers of cultured resting zone chondrocytes. Chondrocytes extracted from the resting zone cartilage of ribs from fetal, 4-, and 16-week-old rabbits were cultured and the number of cells was counted in ten random fields per well three times per week. The growth curves were modified in order to make them continuous: at each split, the last cell count before the split was divided by the first cell count after the split. All cell counts after the split were multiplied by the quotient of the two cell numbers. Resting zone chondrocytes from animals of different ages underwent a similar number of population doublings.

also assessed the level of DNA methylation in the liver. In contrast to the age-dependent decrease seen in growth plate cartilage, the level of DNA methylation in the liver increased from fetal to 4-, and 16-week-old animals $(P<0 \cdot 001$; Fig. 4D).

\section{Effect of in vitro replication on global DNA methylation}

To determine whether DNA methylation also decreases with replication of growth plate chondrocytes in vitro, the level of DNA methylation was assessed in resting zone chondrocytes derived from rabbits at different ages and then cultured for various times (Fig. 5). In contrast to the decrease of DNA methylation that was detected in vivo, the level of global DNA methylation in cultured resting zone chondrocytes showed a small but significant increase with each population doubling (percent methylated $\mathrm{dCMP}=62 \cdot 28+0 \cdot 21 \times$ number of population doublings, $P=0.012$ (Fig. 5)) from population doubling four throughout replicative senescence and did not appear to be dependent on donor age $(P=0 \cdot 068)$.

\section{Discussion}

When cultured ex vivo, resting zone chondrocytes initially proliferated but then over time the cumulative number of cells reached a plateau. Thus, resting zone chondrocytes, like many other cell types cultured ex vivo, undergo the Hayflick phenomenon. These chondrocytes underwent approximately 14 population doublings before reaching this plateau. This number is greater than that observed for articular chondrocytes from adult rabbits (eight to ten population doublings) but less than that observed for articular chondrocytes from young adult humans (35-40 population doublings) (Evans \& Georgescu 1983). When the number of cultured resting zone chondrocytes was approaching this maximum, the cells expressed $\beta$-galactosidase, a characteristic typical of cells that have undergone replicative senescence (Dimri et al. 1995).

Growth plate chondrocytes also appear to have a limited proliferative capacity in vivo. As the animal ages, proliferation of growth plate chondrocytes slows and finally stops (Weise et al. 2001). In the current study, the proliferation rate of proliferative zone chondrocytes declined approximately 7-fold between 0 and 16 weeks of age. Previous studies suggest that proliferation in vivo is limited by number of cell divisions, not by time per se (Gafni et al. 2001), and thus the limited proliferation of growth plate chondrocytes in vivo resembles the Hayflick phenomenon. We therefore hypothesized that the same mechanisms were responsible for the two phenomena. However, our data did not support that hypothesis. The number of population doublings of resting zone chondrocytes in culture did not depend on the age of the animal from which the cells were harvested. Thus, previous proliferation in vivo had no effect on subsequent proliferation in vitro. This finding suggests that the mechanisms limiting replicative capacity of growth plate chondrocytes in vivo are distinct from those responsible for limiting replication in vitro. We speculate that the mechanism responsible for limiting proliferation in vivo may require cell-cell and/or cell-matrix interactions that are lost in vitro. As a result, the cultured cells may continue to proliferate until they reach a second stopping point in vitro, the Hayflick limit.

Other studies comparing the replicative potential of cells from adult donors at various ages have in some cases demonstrated a negative correlation between donor age and in vitro replicative capacity (Evans \& Georgescu 1983, Cristofalo \& Pignolo 1993), suggesting that the in vitro replicative capacity of several cell types decreases during aging. However, these previous studies typically involved animals well past the time at which adult body size is attained and thus these previous findings may reflect the degenerative aspects of aging that occur in the latter part of the lifespan, whereas our findings may reflect the developmental aspects of aging that occur in the early part of the lifespan. Furthermore, this reported decline in replicative capacity with age has been questioned (Cristofalo et al. 1998).

In our study, we assessed changes in cell numbers over time. This change in cell number could be affected both by proliferation and by cell death, including apoptosis. 


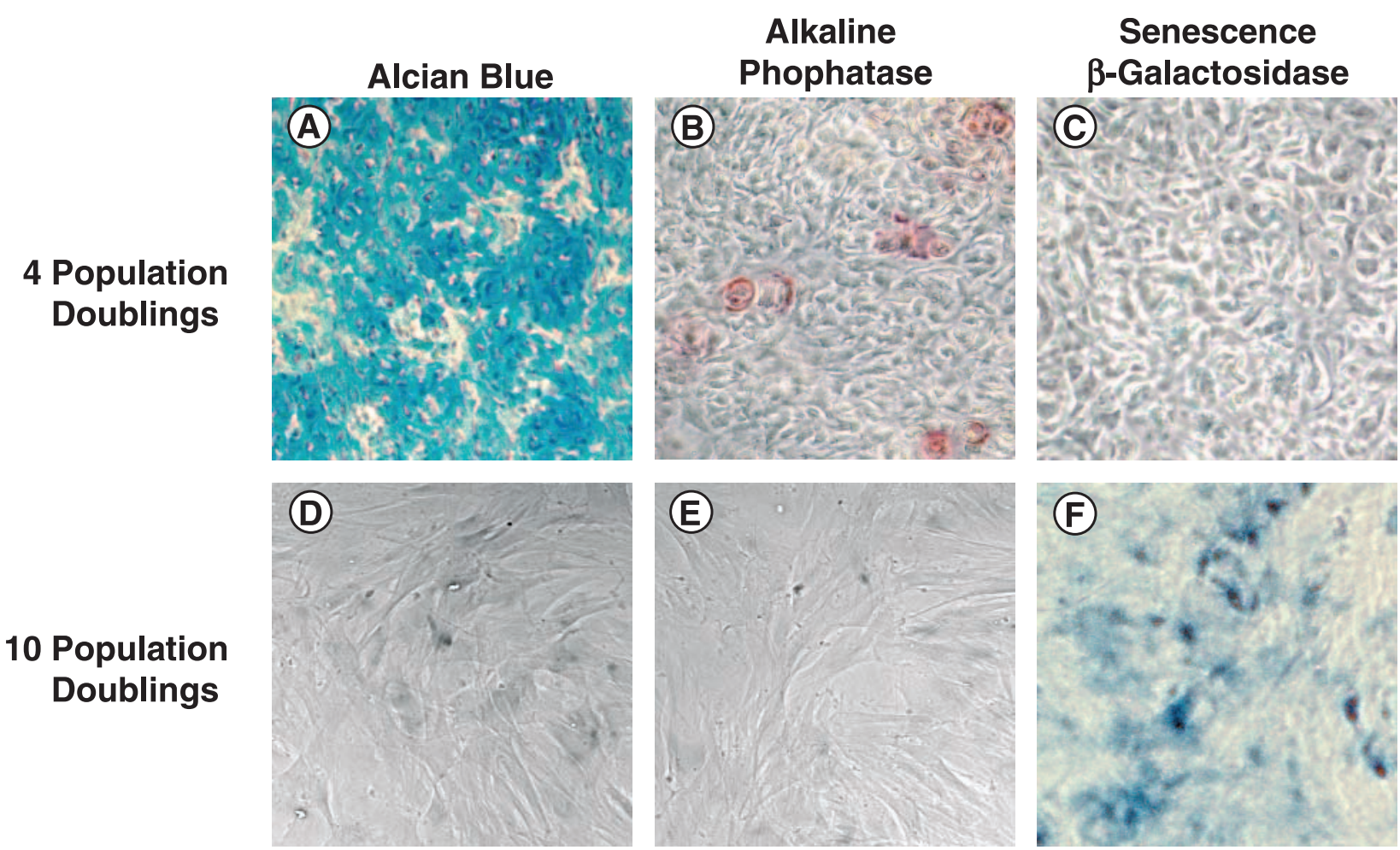

Figure 3 Phenotype of cultured resting zone chondrocytes during replicative senescence. Representative microphotographs of fetal resting zone chondrocytes at population doublings $(A-C)$ four and $(D-E)$ ten stained with alcian blue stain $(A$ and $D)$, and for alkaline phosphatase ( $B$ and $E$ ) and senescence related $\beta$-galactosidase activity $(C$ and $F$ ). Chondrocytes cultured for extended periods of time exhibited decreased staining for alcian blue and alkaline phosphatase activity, but an up-regulation of senescence related $\beta$-galactosidase activity. Bar represents $50 \mu \mathrm{m}$.

In vivo, the decline in proliferation largely explains the decline in growth rate with age (Walker \& Kember 1972), but a decline in cell hypertrophy, matrix production, and possibly an increase in apoptosis may also contribute to the decrease in growth rate (Walker \& Kember 1972, Chrysis et al. 2002).

Proliferation in vitro and in vivo might be limited by cell-division counters, mechanisms that are progressively modified by each cell division (Campisi 1997). Telomere erosion may serve as one such counter that contributes to replicative senescence in vitro and/or to crisis, a later growth-arrest point that cultured cells reach if senescence is bypassed. In human articular chondrocytes, average telomere length decreases with donor age (Martin \& Buckwalter 2001). However, forced expression of the catalytic portion of telomerase does not increase their in vitro life span (Martin et al. 2002). For growth plate chondrocytes in vivo, three lines of evidence suggest that telomere shortening is not the primary cell-division counter causing replicative senescence. First, telomere length varies widely among different strains of mice with similar skeletal sizes (Hemann \& Greider 2000). Indeed, some strains of mice have far greater telomere lengths than humans. Thus, telomere length does not correlate with skeletal size. Secondly, functional ablation of telomerase in mice leads to progressive shortening of telomere length in subsequent generations of the mice but has little effect on skeletal size (Blasco et al. 1997). Thirdly, telomere length does not decrease significantly with growth plate senescence in mice (Nwosu et al. 2005).

We hypothesized that the resting zone chondrocytes undergo a progressive loss of DNA methylation with each cell division and that this loss of methylation serves as a cell-cycle counter that underlies growth plate senescence and limits proliferation. This loss of DNA methylation could occur as these resting zone chondrocytes gradually replicate if there is incomplete maintenance methylation of the newly synthesized strand of DNA. Consistent with this hypothesis, we found that growth plate senescence is associated with a loss of DNA methylation in rib resting zone chondrocytes. Loss of DNA methylation was also observed in the resting zone chondrocytes of the distal ulna. Furthermore, in the distal ulna, a similar loss of methylation with age was observed in the proliferative and hypertrophic zone chondrocytes which are thought to be progeny of the resting zone chondrocytes (Abad et al. 2002). However, within each age, there was no significant difference in the level of DNA methylation between the 
(A)
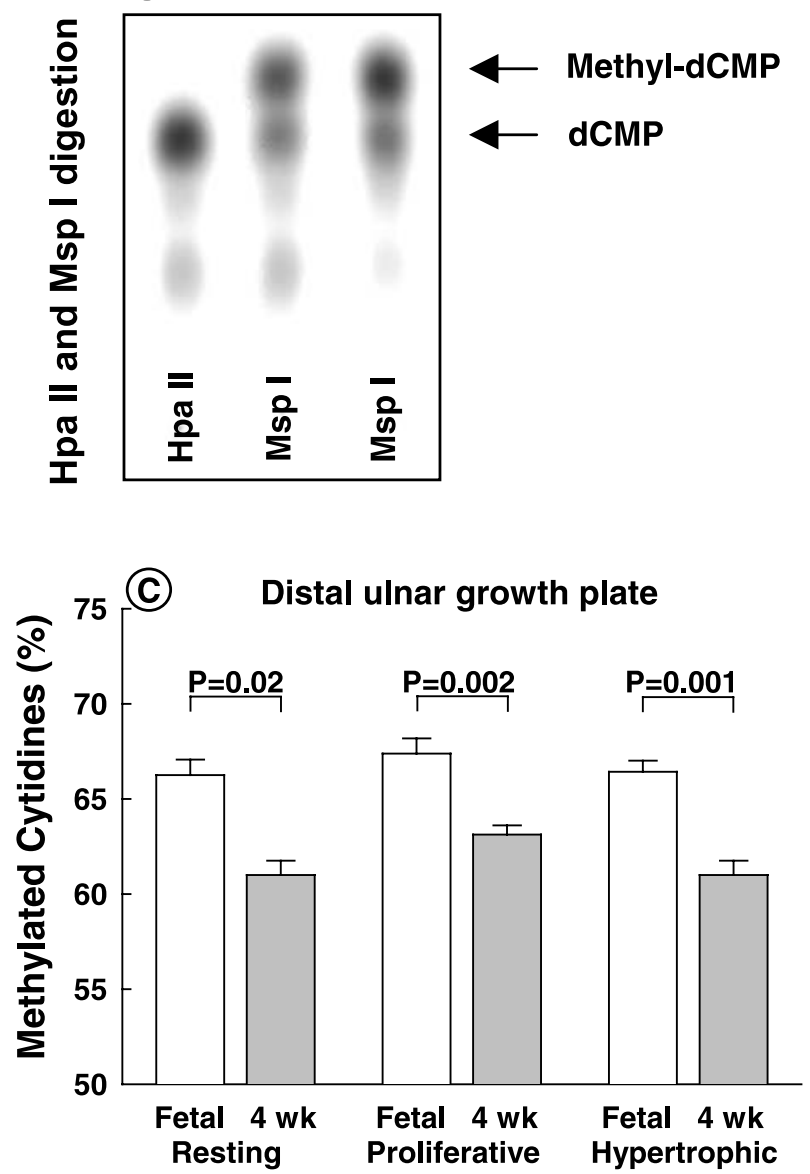

(B) Rib resting zone
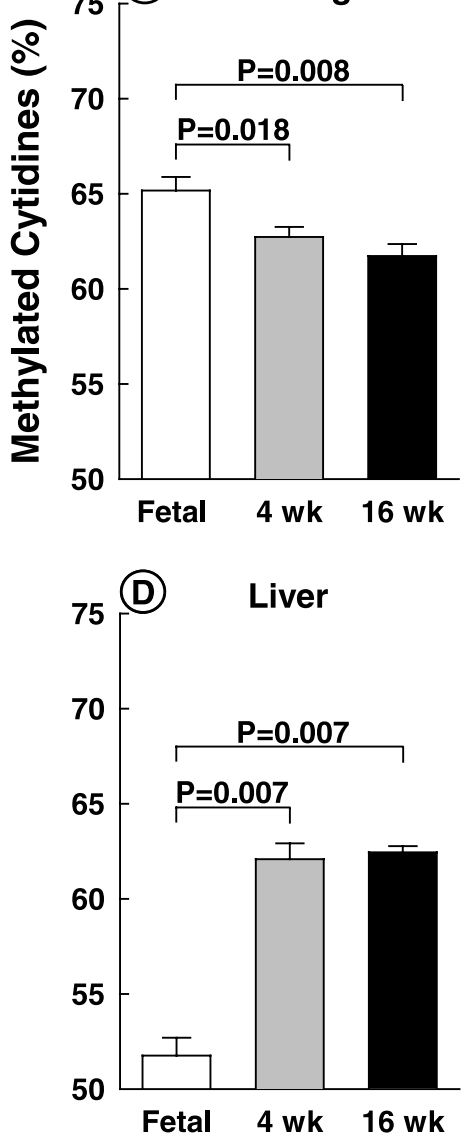

Figure 4 Age-dependent changes in DNA methylation in growth plate cartilage and liver. (A) Labeled deoxynuclotides from CCGG sites were produced by digestion of rabbit DNA with the restriction endonuclease Mspl or, as a control, its methyl-sensitive isoschizomer Hpall, 5' end labeling, nuclease P1 digestion, and thin-layer chromatography. The level of DNA methylation was calculated as 100 times the radioactivity in the methyl-dCMP spot divided by the sum of the radioactivity in the methyl-dCMP spot and the dCMP spot. (B) DNA methylation decreased with age in rib resting zone cartilage and in the individual zones of the growth plate of the $(C)$ distal ulna, but not in (D) the liver. (B and D) Wilcoxon rank-sum tests adjusted for multiple comparison; (C) $t$-tests corrected for multiple comparison.

different zones of the growth plate. Therefore, loss of methylation appears to occur specifically during replication of resting zone chondrocytes but not during the more rapid proliferation of proliferative zone chondrocytes. Thus there may be complete maintenance methylation in the proliferative zone, but not in the resting zone. This finding suggests that loss of methylation might be responsible for the temporal limits that cause chondrocyte replication to slow with age but not the spatial limits that cause chondrocyte proliferation to slow as the cells descend farther down the chondrocyte columns. The spatial limitation on proliferation may not be controlled by a cellcycle counter, but instead it may be controlled by a chemical gradient, e.g. parathyroid hormone-related protein (Chung et al. 2001).
The level of DNA methylation did not decrease during in vitro replication, again suggesting that loss of DNA methylation is not an obligate consequence of chondrocyte proliferation, but rather a specific property of proliferation of resting zone chondrocytes in vivo. This constant level of methylation in vitro also suggests that maintenance methylases were upregulated when the resting zone chondrocytes were placed in cell culture, either because of loss of cell-cell or cell-matrix interactions or because of factors present in culture medium, or other conditions in vitro. This finding is also consistent with our previous inference that the mechanisms limiting replication of growth plate chondrocytes in vitro differ from those in vivo.

To determine whether loss of DNA methylation occurred with age in tissues other than the growth plate 


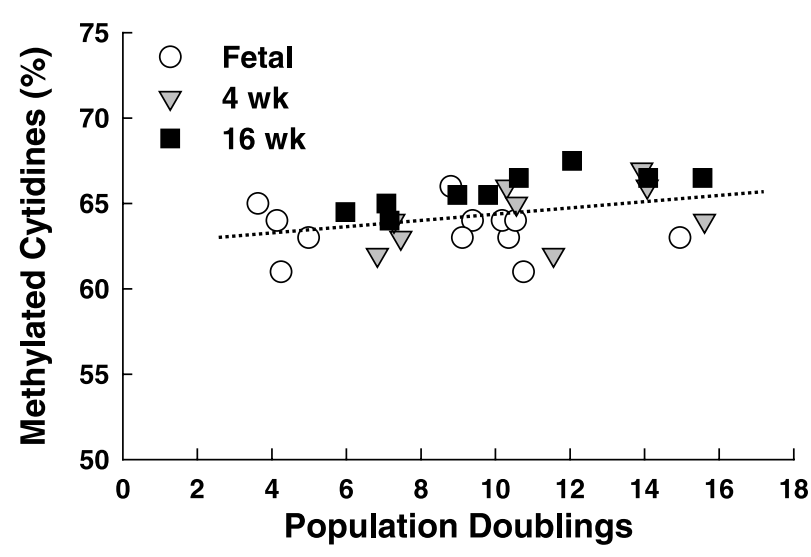

Figure 5 DNA methylation of cultured resting zone chondrocytes during replicative senescence. The level of DNA methylation at Mspl sites was assessed in cultured chondrocytes extracted from rib resting zone cartilage of fetal, 4-, and 16-week-old rabbits. The level of DNA methylation showed a small but significant increase with each population doubling: methylated $\mathrm{dCMP}=62 \cdot 28+0 \cdot 21 \times$ number of population doublings. $P=0.012$ by a repeated measures linear model.

in vivo, we measured methylation levels in the rabbit liver. In liver, the level of methylation actually increased during the first 4 weeks of life and then changed little during the next 12 weeks of life. Thus, loss of methylation with age was not observed in the liver and therefore appears to have some tissue specificity. If loss of DNA methylation represents a mechanism leading to replicative senescence during the early part of the lifespan in some cell types, the absence of this mechanism in hepatic cells might help explain the ability of the adult liver to regenerate after partial hepatectomy.

Previous studies also support the hypothesis that growth plate chondrocyte proliferative capacity may be regulated by DNA methylation. Growth plate chondrocytes cultured at high density and briefly exposed to 5-azacytidine, a demethylating agent, differentiate and start expressing markers specific for hypertrophic chondrocytes (Cheung et al. 2001). In mice, disruption of PASG (proliferation associated SNF2-like gene), causes a loss of genomic DNA methylation. These mice exhibit general growth retardation and evidence of premature cellular senescence in many tissues. Longitudinal bone growth is impaired, although it is not clear whether this effect on skeletal growth is a direct effect of DNA hypomethylation on growth plate chondrocytes or an indirect effect related to systemic disease (Sun et al. 2004). The method used in this study measures methylation at CCGG sequences which might not be representative of all possible CG sites.

In summary, our findings suggest that the mechanisms responsible for limiting proliferation of growth plate chondrocytes in vivo are distinct from the mechanisms limiting proliferation in vitro (the Hayflick phenomenon). We also observed that the level of DNA methylation in resting zone chondrocytes decreased with age in vivo. This loss of methylation appeared to occur specifically with the slow proliferation of resting zone chondrocytes in vivo. Methylation levels did not decrease during proliferation of chondrocytes in vitro, with the rapid proliferation of proliferative zone chondrocytes in vivo (i.e. the level of DNA methylation did not change from the resting zone to the hypertrophic zone) or with growth of the liver in vivo. Taken together our findings are consistent with the hypothesis that the mechanism limiting replication of growth plate chondrocytes in vivo involves specific loss of DNA methylation in the stem-like cells of the resting zone. However, additional studies are needed to determine whether this association between loss of methylation and growth plate senescence represents a direct causal link.

\section{Acknowledgements}

This study was supported by the Swedish MRC (K200372PK-15191-01A), the Swedish Medical Society, Stiftelsen BLANCEFLOR Boncompagni-Ludovisi, född Bildt, Sällskapet Barnavård, Stiftelsen Frimurare Barnhuset i Stockholm, and Wera Ekströms Stiftelse. J B is a Commissioned Officer in the United States Public Health Service. The authors declare that there is no conflict of interest that would prejudice the impartiality of this scientific work.

\section{References}

Abad V, Meyers JL, Weise M, Gafni RI, Barnes KM, Nilsson O, Bacher JD \& Baron J 2002 The role of the resting zone in growth plate chondrogenesis. Endocrinology 143 1851-1857.

Baron J, Klein KO, Colli MJ, Yanovski JA, Novosad JA, Bacher JD \& Cutler GB Jr 1994 Catch-up growth after glucocorticoid excess: a mechanism intrinsic to the growth plate. Endocrinology 135 1367-1371.

Bestor TH, Hellewell SB \& Ingram VM 1984 Differentiation of two mouse cell lines is associated with hypomethylation of their genomes. Molecular and Cellular Biology 4 1800-1806.

Blasco MA, Lee HW, Hande MP, Samper E, Lansdorp PM, DePinho RA \& Greider CW 1997 Telomere shortening and tumor formation by mouse cells lacking telomerase RNA. Cell 91 25-34.

Campisi J 1997 The biology of replicative senescence. European Journal of Cancer 33 703-709.

Cheung JO, Hillarby MC, Ayad S, Hoyland JA, Jones CJ, Denton J, Thomas JT, Wallis GA \& Grant ME 2001 A novel cell culture model of chondrocyte differentiation during mammalian endochondral ossification. Journal of Bone and Mineral Research 16 309-318.

Chrysis D, Nilsson O, Ritzen EM \& Savendahl L 2002 Apoptosis is developmentally regulated in rat growth plate. Endocrine $\mathbf{1 8}$ 271-278.

Chung UI, Schipani E, McMahon AP \& Kronenberg HM 2001 Indian hedgehog couples chondrogenesis to osteogenesis in endochondral bone development. Journal of Clinical Investigation 107 295-304.

Cristofalo VJ \& Pignolo RJ 1993 Replicative senescence of human fibroblast-like cells in culture. Physiological Reviews 73 617-638. 
Cristofalo VJ, Allen RG, Pignolo RJ, Martin BG \& Beck JC 1998 Relationship between donor age and the replicative lifespan of human cells in culture: a reevaluation. PNAS 95 10614-10619.

Dimri GP, Lee X, Basile G, Acosta M, Scott G, Roskelley C, Medrano EE, Linskens M, Rubelj I, Pereira-Smith O et al. 1995 A biomarker that identifies senescent human cells in culture and in aging skin in vivo. PNAS 92 9363-9367.

Eden S, Hashimshony T, Keshet I, Cedar H \& Thorne AW 1998 DNA methylation models histone acetylation. Nature 394842.

Evans CH \& Georgescu HI 1983 Observations on the senescence of cells derived from articular cartilage. Mechanisms of Ageing and Development 22 179-191.

Fairweather DS, Fox M \& Margison GP 1987 The in vitro lifespan of MRC-5 cells is shortened by 5 -azacytidine-induced demethylation. Experimental Cell Research 168 153-159.

Gafni RI, Weise M, Robrecht DT, Meyers JL, Barnes KM, De Levi S \& Baron J 2001 Catch-up growth is associated with delayed senescence of the growth plate in rabbits. Pediatric Research $\mathbf{5 0}$ $618-623$.

Goldstein S \& Singal DP 1974 Senescence of cultured human fibroblasts: mitotic versus metabolic time. Experimental Cell Research 88 359-364.

Hayflick L 1965 The limited in vitro lifetime of human diploid cell strains. Experimental Cell Research 37 614-636.

Hayflick L \& Moorhead P 1961 The serial cultivation of human diploid cell strains. Experimental Cell Research 25 585-621.

Hemann MT \& Greider CW 2000 Wild-derived inbred mouse strains have short telomeres. Nucleic Acids Research 28 4474-4478.

Holliday R 1985 The significance of DNA methylation in cellular aging. Basic Life Science 35 269-283.

Jones PA \& Laird PW 1999 Cancer epigenetics comes of age. Nature Genetics 21 163-167.

Kaji K \& Matsuo M 1979 Doubling potential and calendar time of human diploid cells in vitro. Experimental Gerontology 14 329-334.

Martin JA \& Buckwalter JA 2001 Telomere erosion and senescence in human articular cartilage chondrocytes. Journals of Gerontology: Series A Biological Sciences and Medical Sciences 56 B172-B179.

Martin JA, Mitchell CJ, Klingelhutz AJ \& Buckwalter JA 2002 Effects of telomerase and viral oncogene expression on the in vitro growth of human chondrocytes. Journals of Gerontology: Series A Biological Sciences and Medical Sciences 57 B48-B53.

Masoud I, Shapiro F, Kent R \& Moses A 1986 A longitudinal study of the growth of the New Zealand white rabbit: cumulative and biweekly incremental growth rates for body length, body weight, femoral length, and tibial length. Journal of Orthopedic Research 4 221-231.
National Research Council 2003 Guide for the Care and Use of Laboratory Animals. Washington, DC: National Academy Press.

Nwosu BU, Nilsson O, Mitchum RD Jr, Coco M, Barnes KM \& Baron J 2005 Lack of telomere shortening with age in mouse resting-zone chondrocytes. Hormonal Research 63 125-128.

Shapiro F, Holtrop ME \& Glimcher MJ 1977 Organization and cellular biology of the perichondrial ossification groove of ranvier: a morphological study in rabbits. Journal of Bone and Joint Surgery 59 703-723.

Stanulis-Praeger BM 1987 Cellular senescence revisited: a review. Mechanisms of Ageing and Development 38 1-48.

Stein R, Gruenbaum Y, Pollack Y, Razin A \& Cedar H 1982 Clonal inheritance of the pattern of DNA methylation in mouse cells. PNAS 79 61-65.

Stevens DG, Boyer MI \& Bowen CV 1999 Transplantation of epiphyseal plate allografts between animals of different ages. Journal of Pediatric Orthopedics 19 398-403.

Sun LQ, Lee DW, Zhang Q, Xiao W, Raabe EH, Meeker A, Miao D, Huso DL \& Arceci RJ 2004 Growth retardation and premature aging phenotypes in mice with disruption of the SNF2-like gene, PASG. Genes and Development 18 1035-1046.

Walker KV \& Kember NF 1972 Cell kinetics of growth cartilage in the rat tibia. II. Measurements during ageing. Cell and Tissue Kinetics 5 409-419.

Weise M, De-Levi S, Barnes KM, Gafni RI, Abad V \& Baron J 2001 Effects of estrogen on growth plate senescence and epiphyseal fusion. PNAS 98 6871-6876.

Wigler M, Levy D \& Perucho M 1981 The somatic replication of DNA methylation. Cell 24 33-40.

Wilson VL \& Jones PA 1983 DNA methylation decreases in aging but not in immortal cells. Science 220 1055-1057.

Wroblewski J \& Edwall-Arvidsson C 1995 Inhibitory effects of basic fibroblast growth factor on chondrocyte differentiation. Journal of Bone and Mineral Research 10 735-742.

Young JI \& Smith JR 2001 DNA methyltransferase inhibition in normal human fibroblasts induces a p21-dependent cell cycle withdrawal. Journal of Biological Chemistry 276 19610-19616.

Received 17 March 2005

Accepted 6 April 2005

Made available online as an Accepted Preprint

19 April 2005 